\title{
POTENCIAL DE TRANSFERÊNCIA DE SEDIMENTOS E SUSCETIBILIDADE A ASSOREAMENTOS DA REDE HIDROGRÁFICA DO ALTO RIO ARAGUAIA
}

\author{
POTENTIAL OF SEDIMENT TRANSFERRING AND SUSCEPTIBLE \\ TO AGGRADATION OF THE HYDROGRAPHIC NETWORK OF THE \\ UPPER COURSE ARAGUAIA RIVER
}
POTENCIAL DE TRANSFERENCIA DE SEDIMENTOS Y SUSCEPTIBILIDAD A LA SEDIMENTACIÓN DE GRANDES VOLÚMENES DE MATERIALES EN LA RED HIDROGRÁFICA DEL ALTO RÍO ARAGUAIA

\author{
Márcio Henrique de Campos Zancopé - Universidade Federal de Goiás - Goiânia - Goiás - Brasil \\ zancope@ufg.br \\ Paulo Eduardo Gonçalves - Universidade Federal de Goiás - Goiânia - Goiás - Brasil \\ pauloeg.geoambiental@gmail.com \\ Maximiliano Bayer - Universidade Federal de Goiás - Goiânia - Goiás - Brasil \\ maxbayer@ufg.br
}

\section{Resumo}

A rede hidrográfica do alto curso do rio Araguaia é responsável por captar e transferir a carga sedimentar presente no médio curso. Partes da rede executam esse trabalho com graus diferentes de eficiência. Assim, este artigo avalia o potencial de transferência de sedimentos das sub-bacias do alto curso superior do Araguaia e aponta trechos fluviais suscetíveis a assoreamento. Sub-bacias com potencial de transferência de sedimentos elevado são eficientes em liberar sua carga sedimentar, contribuindo com a carga do Araguaia e as com potenciais reduzidos são pouco eficientes em liberar a carga sedimentar, estando suscetíveis à agradação. 0 s potenciais de transferência foram determinados, em ambiente SIG, pela combinação de parâmetros morfométricos da rede de drenagem, enquanto os trechos suscetíveis a assoreamento pela combinação dos graus de potências de transferência, análise da forma dos perfis longitudinais e da distribuição das planícies fluviais. A bacia do alto curso superior do Araguaia apresenta três sub-bacias com potencial de transferência de sedimentos médiobaixo, três com potencial médio, duas com médio-alto e quatro com potencial alto. Aquelas com potenciais elevados predominam no norte dessa bacia, enquanto os trechos com assoreamento predominam na parte intermediária.

Palavras-chave: morfometria fluvial, perfil longitudinal, transporte sedimentar.

\begin{abstract}
The hydrographic network of the upper course of the Araguaia River is responsible to capture and discharge its sedimentary load to the middle course. Parts of the hydrographic network do this work with different degrees of efficiency. This paper evaluates the potential of sediment transferring from hydrographic network of the upper course of the Araguaia and indicates stretches of fluvial channels susceptible to aggradation. Sub-basins with higher potential of sediment transferring are efficient to discharge its sedimentary load into the Araguaia River, while sub-basins with lower potential are inefficient to do that work, being susceptible to aggradation. The potentials of sediment transferring were determinate with SIG software by combination of morphometric parameters of the hydrographic network, while stretches susceptible to aggradation by combination between those potentials, the longitudinal profiles and distribution of the floodplains. The network of the upper course of
\end{abstract}


the Araguaia River presented three sub-basins with medium-low potential of sediment transferring, two subbasins with medium potential, two with medium-high potential and four sub-basins with high potential. The sub-basins with higher potentials of sediment transferring are located at North from study area, while stretches susceptible to aggradation are located in the central part of the study area.

Key words: fluvial morphometry, longitudinal profile, sediment transport.

\section{Resumen}

La red hidrográfica del alto curso del Río Araguaia es la responsable por captar y transferir la carga sedimentar al trecho medio del río, ejecutando ese papel con diferentes grados de eficiencia. Este artículo evalúa el potencial de transferencia de sedimentos de las sub-cuencas del alto curso del río Araguaia y apunta tramos de los canales fluviales susceptibles a la sedimentación de grandes volúmenes de materiales. Las sub-cuencas con elevado potencial de transferencia son eficientes en liberar la carga de sedimentos, aumentando así la carga transportada por el río Araguaia. Las sub-cuencas que muestran potenciales reducidos son poco eficientes en la liberación de las cargas de sedimentos, mostrando una importante acumulación de materiales en las llanuras de inundación de los canales principales. Los potenciales de transferencia de sedimentos fueron determinados, en ambiente GIS, por la combinación de parámetros morfométricos de la red de drenaje, y en los trechos susceptibles a la deposición por la combinación del potencial de transferencia, análisis de los perfiles longitudinales y por la morfología y distribución de las llanuras de inundación. La cuenca del alto curso del río Araguaia presenta tres sub-cuencas con Medio a Bajo potencial, tres sub-cuencas con potencial Medio, dos con Alto a Medio potencial de transferencia de materiales y cuatro sub-cuencas con Alto potencial. Las sub-cuencas con potencial elevado son características del sector Norte de la cuenca del alto río Araguaia, mientras que los trechos de los canales con sedimentación activa predominan en el sector intermedio de la cuenca.

Palabras clave: morfometría fluvial, perfil longitudinal, transporte de sedimentos.

\section{Introdução}

No trecho do médio curso do rio Araguaia, entre as cidades goianas de Aragarças e Luiz Alves, foi verificado o aumento de $31 \%$ da carga do leito (fundo) no período de 1965 a 1998 (Latrubesse et al., 2009). A carga passou de 6,6 milhões de toneladas de sedimentos em 1965 para 8,8 milhões de toneladas em 1998. Esse aumento, possivelmente, se deve ao desmatamento do Cerrado e às práticas agrícolas não conservacionistas durante o mesmo período, uma vez que essas ações teriam intensificados os processos erosivos nas vertentes, lançando maior quantidade de detritos nos afluentes do alto curso do rio, os quais acabariam sendo transportados para o médio curso.

Aquino, Stevaux e Latrubesse (2005) observaram comportamentos morfo-hidráulicos distintos entre o alto e o médio curso do rio Araguaia. $\mathrm{O}$ alto curso escoa sobre leito rochoso enquanto o médio Araguaia escoa sobre aluviões de extensa planície, demonstrando a suscetibilidade para mudanças nos mecanismos de transporte e/ou deposição da carga sedimentar. 
De fato, há grande ocorrência de focos de erosão acelerada na região da bacia do alto curso do rio Araguaia (Borges et al., 2009; Oliveira e Castro, 2005; Marinho, Castro e Campos, 2006), que são resultado do conflito (discordância) entre os condicionantes físico-naturais (solos arenosos, vertentes longas e convergentes dos fluxos hídricos superficiais e subsuperficiais e pluviosidade concentrada na estação chuvosa) e o manejo agrícola. As incompatibilidades entre a capacidade de uso ou aptidão agrícola e o manejo empregado pelos empreendimentos agropecuários desencadearam a ocorrência elevada desses processos erosivos acelerados (Castro, 2005).

Dessa forma, este artigo apresenta uma avaliação do Potencial de Transferência de Sedimentos da rede hidrográfica do alto curso do rio Araguaia e aponta trechos dos seus cursos fluviais suscetíveis ao assoreamento. O Potencial de Transferência de Sedimentos (PTS) indica a capacidade de uma rede de drenagem transportar sua carga sedimentar através do exutório (Zancopé e Bayer, 2012). Uma sub-bacia, cuja rede de drenagem possui um potencial baixo de transferência de sedimentos, tem capacidade baixa de transporte, estando suscetível a depositar sua carga sedimentar ao longo dos cursos d'água, e vice-versa. Tal avaliação ajuda a verificar se os rios da rede de drenagem da bacia do alto curso do rio Araguaia possuem condições de transportar os sedimentos, resultantes dos processos erosivos acelerados, até o médio curso, convergindo a hipótese do aumento da carga do leito do médio curso ligado aos processos erosivos acelerados na bacia do alto curso (Latrubesse et al., 2009). Por outro lado, as sub-bacias com potencial baixo de transferência de sedimentos não contribuem com o aumento da carga arenosa, revelando estar suscetíveis à ocorrência de assoreamentos em sua rede de drenagem.

\section{Área de estudo}

A área de estudo compreende o setor sul da bacia do alto rio Araguaia (Figura 1), a montante da confluência com o rio Babilônia ( $17^{\circ} 13^{\prime} \mathrm{S}$ e 53 $3^{\circ} 09^{\prime} \mathrm{W}$ ), entre os municípios goianos de Santa Rita do Araguaia e Mineiros (nascente do Araguaia: $18^{\circ} 02^{\prime} \mathrm{S}$ e $53^{\circ} 04^{\prime} \mathrm{W}$ ). Somente as sub-bacias da margem direita do alto curso do rio Araguaia constituem objeto deste estudo, em virtude das restrições do auxílio financeiro da agência de fomento que apoiou esta pesquisa. 


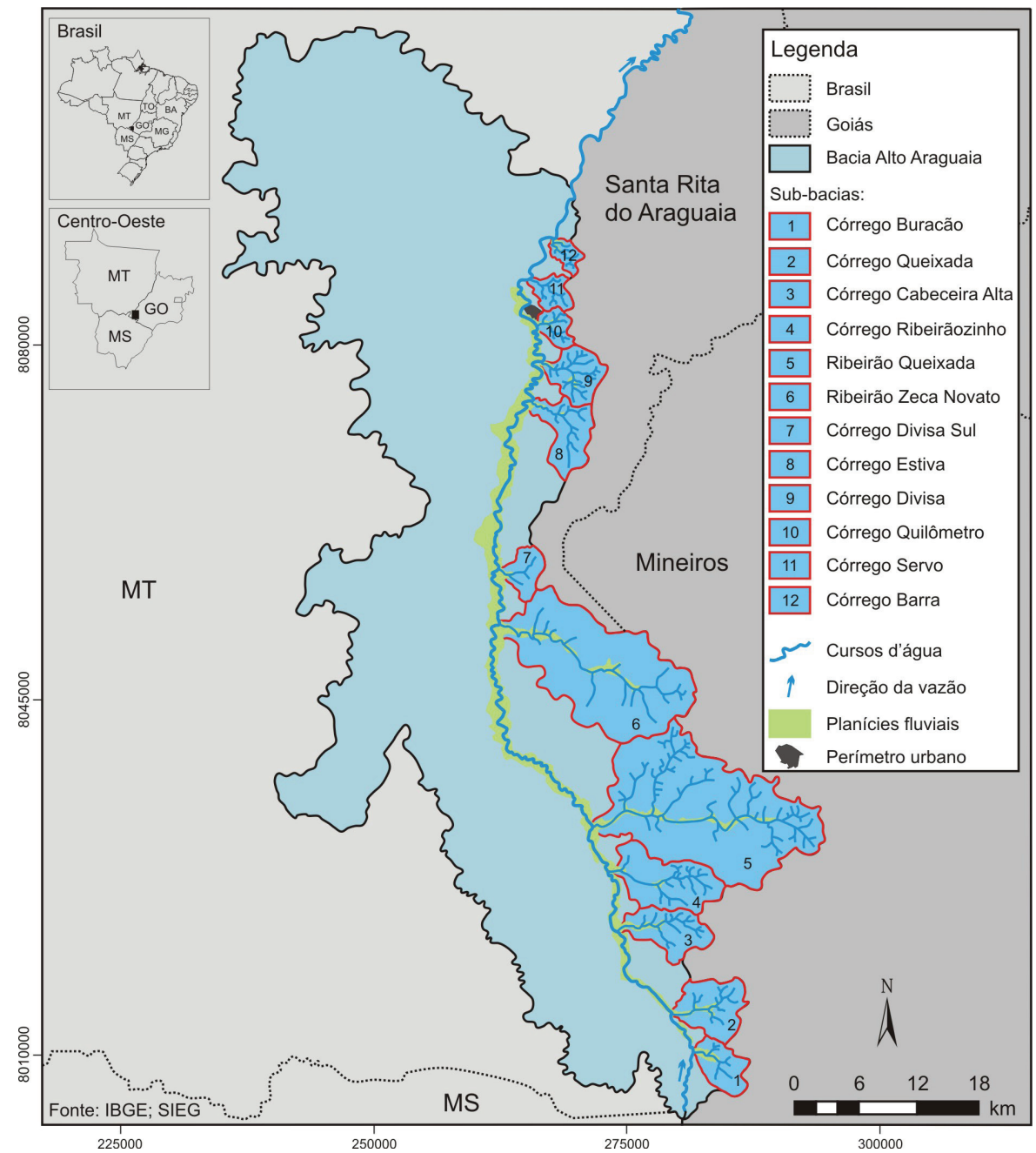

Figura 1- As sub-bacias estudadas no setor sul da bacia do alto rio Araguaia.

Na área de estudo, predomina relevo de colinas baixas e amplas com rampas longas e baixa declividade. Junto aos divisores da bacia do alto Araguaia, apresentam-se escarpas com a presença de cornijas em alguns locais. Há predominância de solos frágeis, decorrentes da associação de Neossolos Quartzarênicos Órticos e subordinariamente Argissolos Vermelho-Amarelos Distróficos e Neossolos Quartzarênicos Hidromórficos 
(Castro, 2005; Oliveira e Castro, 2005; Marinho, Castro e Campos, 2006). O substrato litológico predominante compreende os arenitos jurássicos da Formação Botucatu e, subordinariamente, os basaltos jura-cretácicos da Formação Serra Geral, na parte norte da área (Lacerda Filho, 2000).

\section{Procedimentos metodológicos}

A classificação do PTS da área de estudo baseou-se na determinação e análise de variáveis e em parâmetros morfométricos da rede de drenagem. Os parâmetros investigados foram densidade hidrográfica (Dh); densidade de drenagem (Dd); extensão do percurso superficial (Eps); e gradiente fluvial (Gd) para os rios que constituem os eixos principais das sub-bacias.

A determinação das variáveis partiu do refinamento e ajuste da rede de drenagem obtidos pela análise das orto imagens Alos 2011, disponibilizados pelo IBGE na escala 1:100.000. As variáveis altimétricas foram obtidas a partir do modelo digital de terreno (MDT), cujos dados (SRTM) foram disponibilizados pela Agência Espacial dos Estados Unidos (NASA) e pelo Serviço Geológico dos Estados Unidos (USGS). Os dados e as variáveis morfométricas foram tratados em ambiente SIG, tendo como base a utilização do software ArcGis 10.

Após a determinação das variáveis, os parâmetros morfométricos foram calculados de acordo com Christofoletti (1969). Em seguida, para cada sub-bacia, eles foram classificados de acordo com a metodologia empregada por Meliani (2006). O número de classes foi determinado pela fórmula de Sturges $(k=1+3,3 \cdot \log n)$, onde "k" é o número de classes, "n" é o número total de ocorrência e "log" é o logaritmo para a base 10. Neste estudo, considerando as 12 sub-bacias ( $\mathrm{n}=12$ ), obteve-se $\mathrm{k}=4,05$, estabelecendo 4 classes.

Para se determinar o intervalo de classes de cada parâmetro, foi necessário identificar a média aritmética como medida de tendência central, e o desvio padrão como medida de dispersão. A média aritmética foi calculada adicionando-se o valor referente a cada sub-bacia, e dividindo-se o resultado pelo total de sub-bacias analisadas. Para a obtenção do desvio padrão, foram feitos o cálculo do desvio de cada ocorrência, em relação à média aritmética, e o cálculo da variância de cada um dos parâmetros analisados. A variância foi obtida por meio da divisão da soma 
dos desvios da média elevados ao quadrado pelo número de sub-bacias. O desvio padrão, que é uma medida do desvio dos valores individuais em relação ao valor central do conjunto de dados, foi obtido por meio da raiz quadrada da variância (Meliani, 2006).

Conhecido o desvio padrão, calculou-se quanto cada sub-bacia varia em relação ao desvio padrão; dessa forma, obteve-se a proporção de desvio padrão que cada sub-bacia apresenta em relação à medida de tendência central. O intervalo entre as quatro classes foi elaborado depois de dividir a amplitude total das proporções de desvio padrão pelo número de classes e, assim, multiplicar pelo valor do desvio padrão (Meliani, 2006). Como resultado, foram obtidas duas classes de parâmetros morfométricos que se estabeleceram acima da média aritmética, denominadas Alto e Muito alto, enquanto as duas classes estabelecidas abaixo da média foram denominadas Médio e Baixo.

Após a classificação, os parâmetros morfométricos de cada sub-bacia foram aplicados na matriz (Figura 2) de avaliação do Potencial de Transferência de Sedimentos (Zancopé e Bayer, 2012).

\begin{tabular}{|c|c|c|c|c|}
\hline \multicolumn{4}{|c|}{ Parâmetros Morfométricos } & \multirow{2}{*}{$\begin{array}{c}\text { Potencial de } \\
\text { Transferência } \\
\text { de Sedimentos } \\
\text { (PTS) }\end{array}$} \\
\hline Dd & Dh & Eps & Gd & \\
\hline Alto & Alto & Baixo & Alto & Alto \\
\hline Baixo & Baixo & Alto & Baixo & Baixo \\
\hline
\end{tabular}

Figura 2- Matriz de avaliação do PTS, segundo Zancopé e Bayer (2012).

De acordo com a matriz, sub-bacias cuja combinação de Dh e Dd elevados e Eps baixo, associada com Gd elevados, apresentam PTS elevado. Inversamente, sub-bacias cuja combinação de Dh e Dd baixo e Eps elevado, associada com Gd baixos, apresentam PTS reduzido. Segundo Zancopé e Bayer (2012), essas duas situações representam os extremos da matriz, sendo possíveis haver situações intermediárias, conforme a combinação entre os graus das classes dos parâmetros morfométricos. 
A aplicação da matriz permitiu encontrar o PTS para cada sub-bacia. O perfil longitudinal dos cursos d'água mostra a variação do gradiente desde as nascentes até o exutório. Variações longitudinais no gradiente influenciam o potencial de transferência de sedimentos de uma bacia, pois afetam a energia da corrente fluvial, a ponto de promover o surgimento de trechos com predomínio de agradação, como as planícies fluviais.

De modo a validar as classes de Potencial de Transferência das sub-bacias, foi analisada a forma dos perfis longitudinais dos cursos d'água principais das sub-bacias (eixos da drenagem), associada à distribuição das suas planícies de fluviais. Trechos do perfil longitudinal com gradiente baixo, associado com a presença de planícies fluviais largas, sugerem o predomínio de agradação e suscetibilidade elevada a ocorrer assoreamento, enquanto trechos com gradiente alto, associado à presença de planícies estreitas, sugerem a capacidade de transporte elevada e suscetibilidade reduzida a ocorrer assoreamento (Zancopé e Perez Filho, 2006; Zancopé, Perez Filho e Carpi Júnior, 2009).

Nessa última etapa, os perfis longitudinais e as planícies fluviais foram traçados por meio do Modelo Digital de Terreno (MDT). Para confeccionar os perfis longitudinais, foram gerados os histogramas da relação altitude e distância, cujos dados foram exportados para o Excel $\left(\right.$ MSOffice $^{\circledR}$ ), para eliminar as limitações do MDT.

\section{Resultados e discussões}

\section{Potencial de Transferência de Sedimentos}

A aplicação dos valores relativos dos parâmetros morfométricos na matriz de avaliação do PTS computou três sub-bacias com potencial médio-baixo de transferência de sedimentos, três com potencial médio, duas com médio-alto e quatro com potencial alto. A Tabela 1 apresenta os valores absolutos e relativos dos parâmetros morfométricos e o PTS para cada sub-bacia investigada.

A Figura 3 apresenta a distribuição das sub-bacias com seus respectivos PTS. Na porção sul da bacia do alto Araguaia, predominam as sub-bacias com PTS mais reduzido, enquanto as sub-bacias com PTS mais elevado são predominantes na porção norte. 
Tabela 1- Parâmetros morfométricos indicadores do PTS.

\begin{tabular}{|c|c|c|c|c|c|c|}
\hline & Sub-bacias & $\begin{array}{c}\operatorname{Dd}(\mathrm{km} / \\
\left.\mathrm{km}^{2}\right)\end{array}$ & $\begin{array}{c}\text { Dh (canais/ } \\
\mathrm{km}^{2} \text { ) }\end{array}$ & Eps (m) & $\mathrm{Gd}(\mathrm{m} / \mathrm{m})$ & PTS \\
\hline & & 0.849 & 0.373 & 588.472 & 0.012 & \\
\hline & & Médio & Médio & Baixo & Alto & \\
\hline & C'́ - & 0.701 & 0.31 & 712.891 & 0.007 & Mo di: ba b \\
\hline (2) & 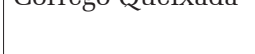 & Médio & Médio & Muito Alto & Médio & 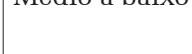 \\
\hline (2) & Córrego Cabeceira & 0.906 & 0.441 & 551.876 & 0.008 & Modi. \\
\hline (3) & Alta & Médio & Médio & Baixo & Médio & Nieuio \\
\hline & Córrego & 0.829 & 0.359 & 588.472 & 0.006 & \\
\hline (I) & Ribeirãozinho & Médio & Médio & Baixo & Médio & 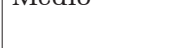 \\
\hline$(5)$ & Dibaiñ Ou- & 0.561 & 0.272 & 890.954 & 0.006 & Módin bava \\
\hline (5) & Knerrao Quesxada & Médio & Médio & Muito Alto & Médio & Nearo a Daixo \\
\hline$(\Omega)$ & Ribeirão Zeca & 0.343 & 0.096 & 1457.725 & 0.004 & C. \\
\hline (b) & Novato & Médio & Médio & Muito Alto & Médio & Medio a balxo \\
\hline & & 1.196 & 0.208 & 418.05 & 0.009 & Modi \\
\hline (1) & Contego Divisd sul & Alto & Médio & Baixo & Médio & IVIEUTo d dito \\
\hline & & 0.851 & 0.311 & 587.32 & 0.006 & \\
\hline (8) & Corrego Estiva & Médio & Médio & Baixo & Médio & Medio \\
\hline & Ć & 1.444 & 0.903 & 346.208 & 0.006 & \\
\hline (9) & Córrego Divisa & Alto & Alto & Baixo & Médio & Alto \\
\hline (10) & Córrego & 1.514 & 0.893 & 330.039 & 0.014 & Alto \\
\hline$(10)$ & Quilômetro & Alto & Alto & Baixo & Alto & HIto \\
\hline & & 1.193 & 0.744 & 419.018 & 0.017 & \\
\hline (11) & Córrego Servo & Alto & Alto & Baixo & Alto & Alto \\
\hline & & 1.542 & 0.841 & 324.181 & 0.023 & \\
\hline$(12)$ & Lor & Alto & Alto & Baixo & Alto & Allo \\
\hline
\end{tabular}




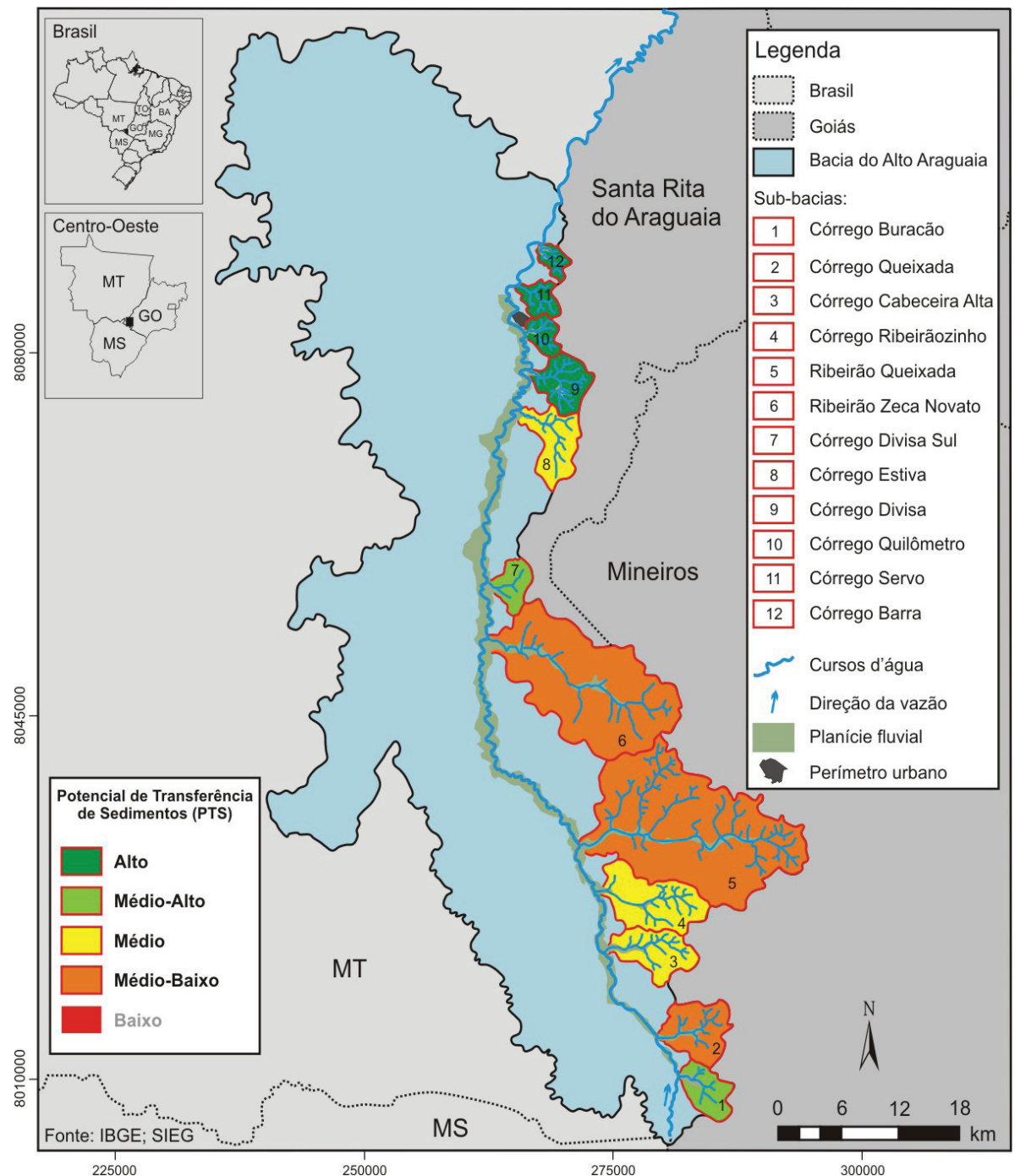

Figura 3- PTS das sub-bacias goianas no setor sul da bacia do alto rio Araguaia.

As sub-bacias da porção sul sofrem influência dos afloramentos dos basaltos da Formação Serra e dos arenitos da Formação Botucatu. Enquanto os basaltos agem como soleira, dificultando o entalhamento do leito e do nível de base local, os arenitos desenvolvem menor densidade 
hidrográfica e de drenagem, atenuando o PTS das sub-bacias da porção sul. Já as sub-bacias da porção norte sofrem influência da proximidade de oito quilômetros a jusante com o trecho encachoeirado do alto Araguaia (Canyon do Araguaia) que produz um nível de base local mais profundo e um gradiente mais elevado, intensificando os potenciais de transferência.

Deve ser lembrado que os graus de PTS encontrados são relativos às sub-bacias avaliadas, exclusivamente. Para comparação com outras áreas, as demais sub-bacias devem ser acrescidas na matriz de avaliação e seus respectivos parâmetros morfométricos comparados entre todos do novo conjunto amostrado.

\section{Perfil longitudinal e distribuição das planícies}

A forma dos perfis longitudinais mostrou variações do gradiente fluvial ao longo dos cursos d'água principais das sub-bacias estudadas (Figura 4).

Pode-se observar que somente os perfis do ribeirão Queixada e do ribeirão Zeca Novato se aproximam da forma dos perfis considerados em equilíbrio, conforme estabelecido por Mackin (1948). Isso está intrinsecamente relacionado ao PTS médio-baixo encontrado para tais sub-bacias, demonstrando a coerência da Matriz de Avaliação do PTS. Nos demais perfis longitudinais, há irregularidades acentuadas na forma, visto que ora apresentam trechos com gradientes maiores que o gradiente entre a nascente e o exutório, ora apresentam a situação contrária. A forma desses perfis longitudinais indica que o PTS de cada sub-bacia não é uniforme, podendo variar de acordo com o gradiente em diferentes trechos do curso d'água principal.

O tipo de distribuição das planícies fluviais colabora com a variação longitudinal do gradiente e do PTS. A variação da largura das planícies fluviais demonstra mudanças das condições de transporte da carga sedimentar dos rios. Segmentos fluviais com planícies amplas indicam predomínio de condições agradacionais, enquanto segmentos com planícies restritas indicam predomínio de condições de transporte da carga sedimentar (Zancopé e Perez Filho, 2006). 

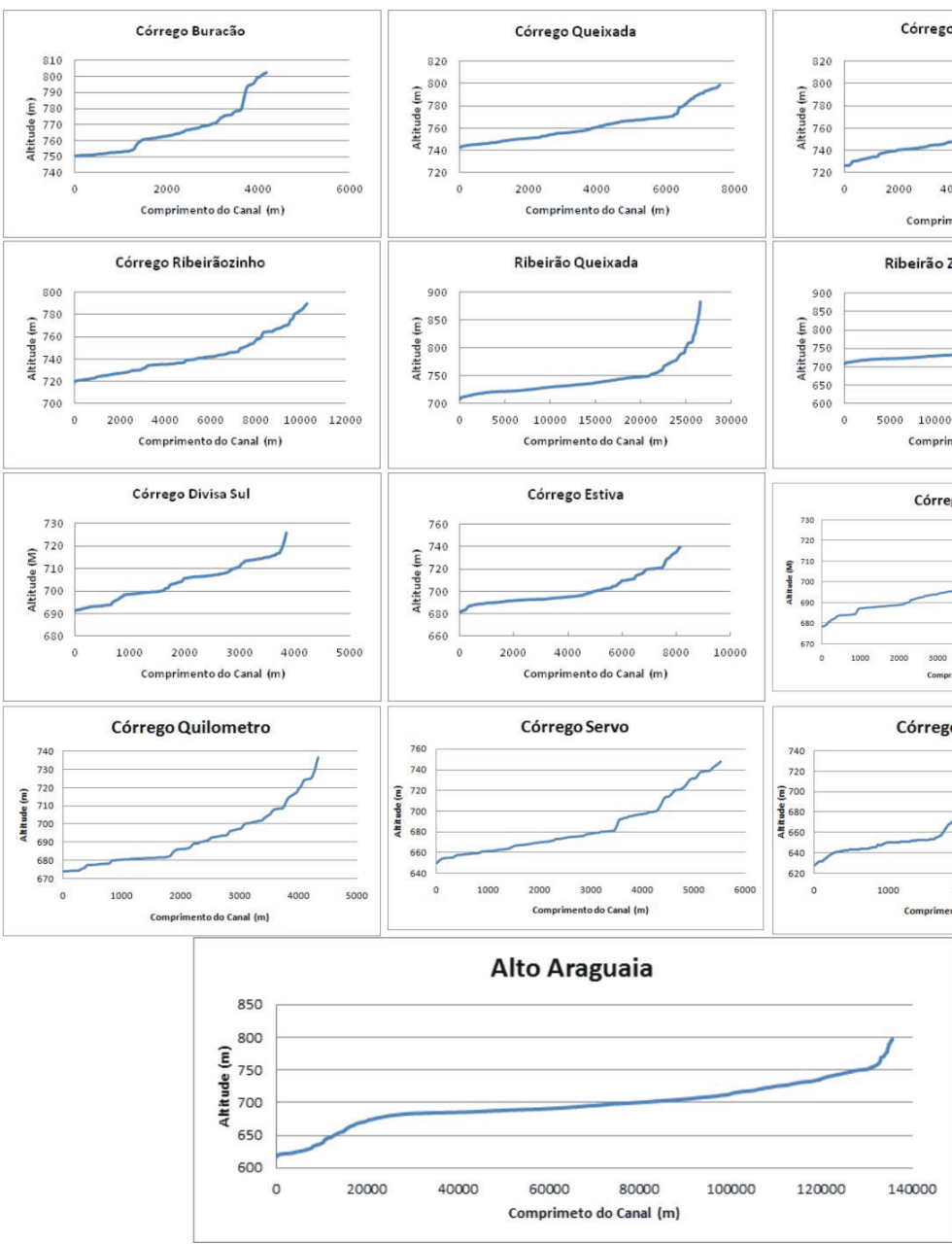

Figura 4- Perfis longitudinais dos eixos das sub-bacias contribuintes goianas do alto Araguaia.

${ }^{*} \mathrm{~A}$ foz dos cursos d'água corresponde ao valor zero no comprimento do canal.

\section{Suscetibilidade ao assoreamento}

A associação entre a forma dos perfis longitudinais, as variações do gradiente fluvial de trechos do perfil e a distribuição das planícies fluviais permitiu revisar o PTS de cada sub-bacia e identificar mudanças nas condições de transporte e trechos fluviais suscetíveis à agradação. 
Dessa forma, foi possível inferir que existem trechos com suscetibilidade a assoreamento, onde ocorreu a combinação de trechos com planícies largas e gradiente reduzido.

A Figura 5 exemplifica a relação existente entre a forma do perfil longitudinal, a distribuição das planícies fluviais e a suscetibilidade à agradação, para a sub-bacia do ribeirão Zeca Novato. O perfil B (Figura 5), em escala semi-log, mostra um detalhamento do segmento 1-2 do perfil A. A sub-bacia do Zeca Novato apresenta um PTS médio a baixo (Tabela 1), indicando dificuldade relativa de liberar os sedimentos produzidos em sua bacia.
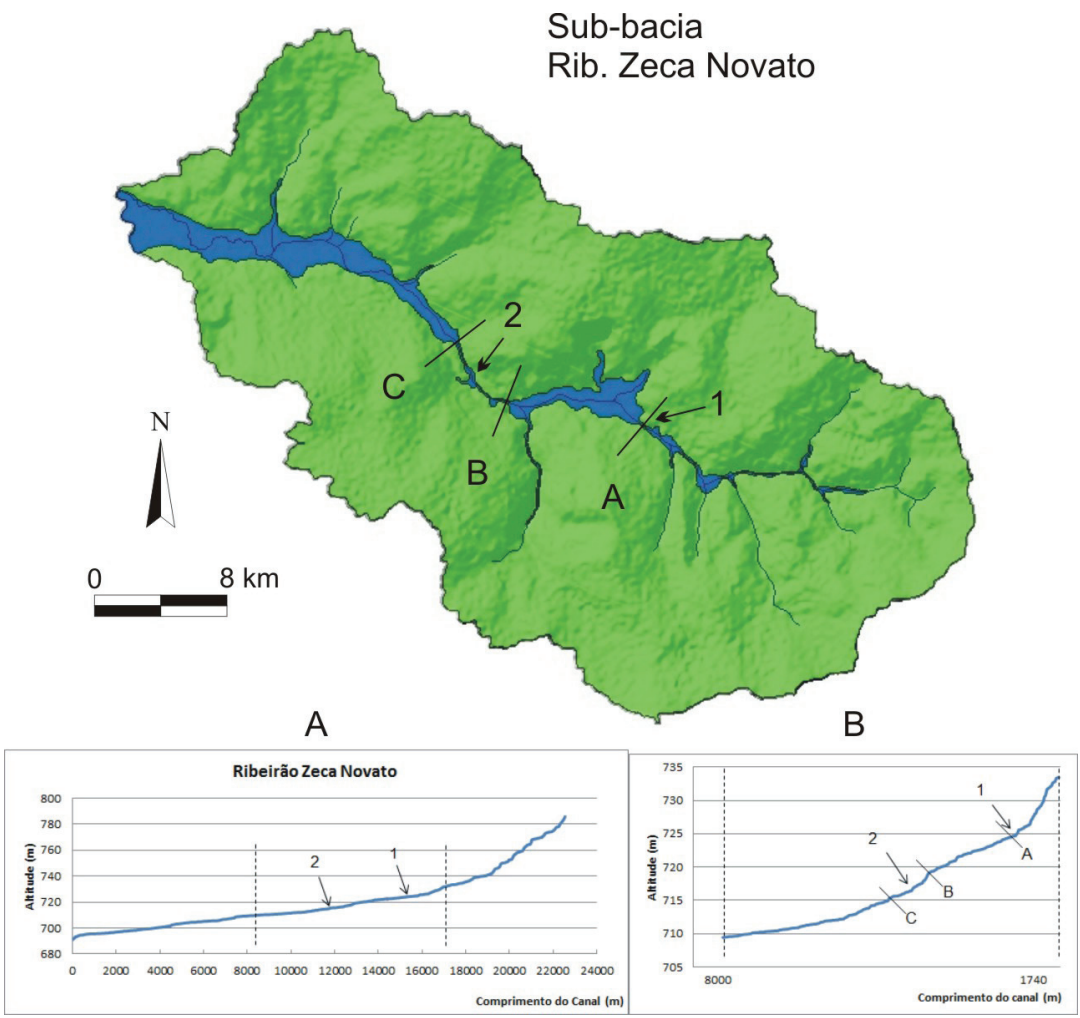

Figura 5- Sub-bacia e perfis longitudinais do ribeirão Zeca Novato.

*As letras e os números são correspondentes entre a sub-bacia e os gráficos. As linhas verticais tracejadas no Gráfico A correspondem ao início e ao fim do trecho fluvial detalhado no Gráfico B. 
A observação do perfil B (Figura 5) permite verificar que o trecho A-B possui gradiente menos acentuado que o trecho B-C. Inversamente, a largura da planície no trecho A-B apresenta-se maior que a do trecho B-C. A jusante da seção $C$, verifica-se a tendência de redução do gradiente e o alargamento da planície. A associação entre o PTS apresentado por essa sub-bacia, o gradiente do perfil e a largura das planícies indica que os trechos $\mathrm{A}-\mathrm{B}$ e a jusante de $\mathrm{C}$ possuem tendência à agradação, enquanto o trecho B-C não apresenta a mesma tendência. Por conseguinte, os trechos A-B e a jusante de $\mathrm{C}$ apresentam-se suscetíveis a assoreamento.

A Figura 6 demonstra a relação similar para a sub-bacia do córrego Estiva, que apresentou um PTS médio (Tabela 1 e Figura 3), indicando moderada liberação de sedimentos produzidos em sua bacia.

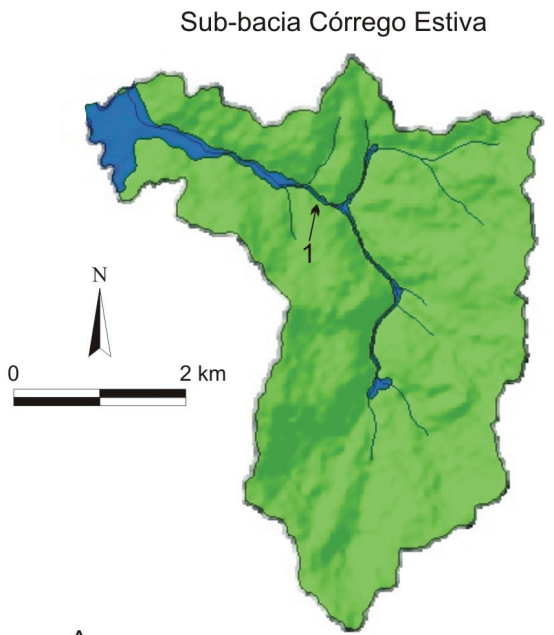

A
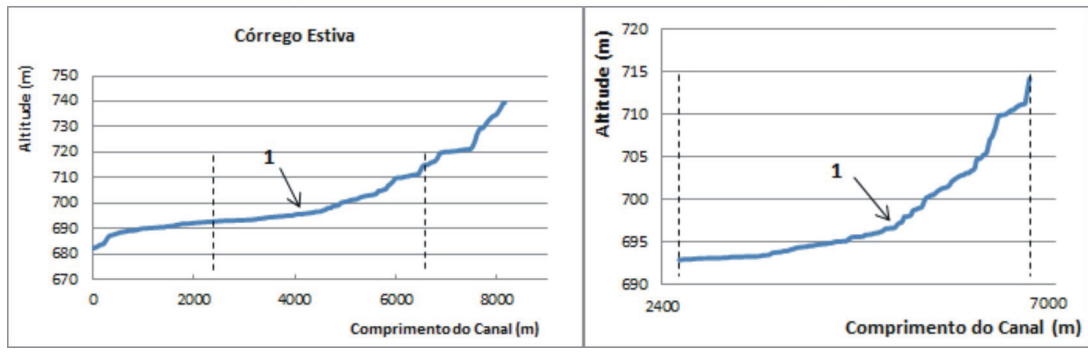

Figura 6- Sub-bacia e perfis longitudinais do córrego Estiva.

* 0 número é correspondente entre a sub-bacia e os gráficos. As linhas verticais tracejadas no Gráfico A correspondem ao início e ao fim do trecho fluvial detalhado no Gráfico B. 
A observação do perfil longitudinal B (Figura 6), em escala semi-log, permite verificar uma inflexão no ponto 1, a partir do qual existe uma tendência de redução do gradiente do perfil a jusante, bem como um alargamento das planícies. A jusante do ponto 1, a redução do gradiente indica predomínio de agradação, inferindo uma suscetibilidade a assoreamento, muito embora a sub-bacia do córrego Estiva apresente condições de liberação de sedimentos moderada (PTS médio).

A Figura 7 apresenta a distribuição das planícies na sub-bacia do córrego Quilômetro, a qual possui PTS alto. Constatam-se gradientes reduzidos e planícies mais largas no trecho B-C e a jusante de D. Dessa forma, esses locais são suscetíveis a assoreamento.
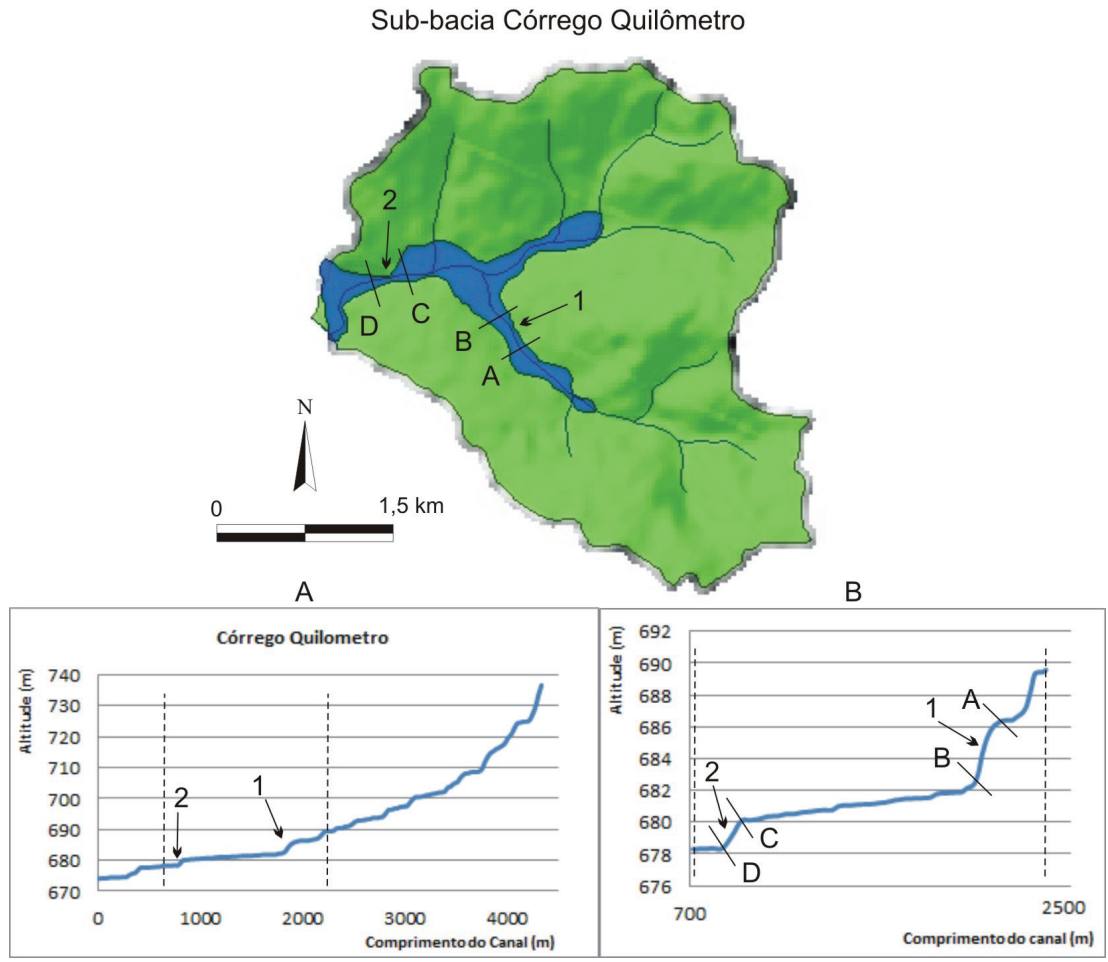

Figura 7- Sub-bacia e perfis longitudinais do córrego Quilômetro.

*As letras e os números são correspondentes entre a sub-bacia e os gráficos. As linhas verticais tracejadas no Gráfico $\mathrm{A}$ correspondem ao início e ao fim do trecho fluvial detalhado no Gráfico B. 
A verificação de trechos dos cursos d'água principais com alargamento das planícies fluviais e gradientes reduzidos, como exemplificado nas Figuras 5, 6 e 7, permitiu identificar os trechos suscetíveis a assoreamento para a toda área de estudo (Figura 8). Tal verificação foi aplicada somente às sub-bacias com PTS médio e médio-baixo. As demais sub-bacias apresentam PTS com capacidade de liberar os sedimentos produzidos em seu interior de forma moderada a elevada, o que implica uma suscetibilidade reduzida de assoreamentos.

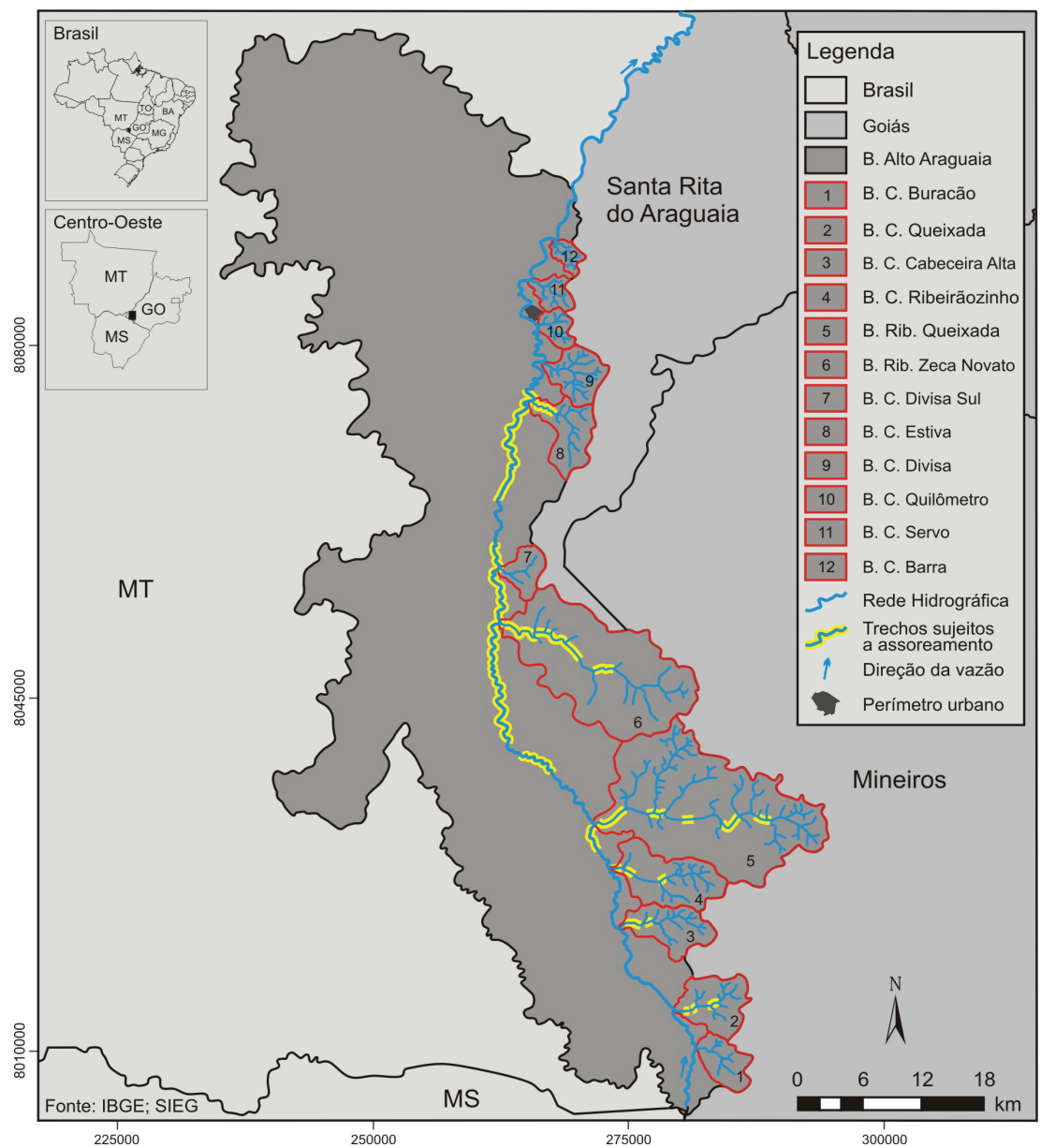

Figura 8- Trechos fluviais suscetíveis a assoreamento das sub-bacias goianas no setor sul da bacia do alto rio Araguaia. 
Deve ser lembrado que os trechos suscetíveis a assoreamento encontrados são relativos às sub-bacias avaliadas, exclusivamente. Para a comparação com outras áreas, as demais sub-bacias devem ser acrescidas na matriz de avaliação do PTS, e seus respectivos parâmetros morfométricos e de distribuição das larguras das planícies fluviais e perfis longitudinais comparados entre todos do novo conjunto amostrado.

\section{Conclusão}

A determinação do PTS apresentou um quadro geral com potenciais entre médio e alto, dentre as 12 sub-bacias avaliadas. Dessa forma, ficou constatado que há quatro sub-bacias com PTS alto, duas com PTS médio-alto, três com PTS médio e três sub-bacias com PTS médio-baixo.

Houve predomínio de PTS mais elevado na parte a jusante (norte) da bacia do alto Araguaia, que estaria relacionado à influência do cânion do Araguaia, a jusante de Santa Rita do Araguaia. Nas partes intermediária e montante da bacia, houve predomínio de sub-bacias com PTS médio, as quais apresentam uma rede de drenagem mais desenvolvida e perfis longitudinais com formas próximas do equilíbrio. Por essas razões, na parte intermediária dessa bacia, houve predomínio de maior quantidade de trechos suscetíveis a assoreamento.

\section{Agradecimentos}

Agradecemos à Fundação de Amparo à Pesquisa do Estado de Goiás (Fapeg) e ao Ministério Público do Estado de Goiás (MPGO) pelo auxílio financeiro a projeto de pesquisa (FAPEG AUX PESQ 003/2010) de 2011 a 2013, bem como ao CNPq pela concessão de bolsa no Programa Institucional de Iniciação Científica (PIBIC) da Universidade Federal de Goiás (UFG), de 2012 a 2013, os quais tornaram possível o desenvolvimento desta pesquisa.

\section{Referências}

AQUINO, S.; STEVAUX, J. C.; LATRUBESSE, E. M. Regime hidrológico e aspectos do comportamento morfo-hidráulico do rio Araguaia. Revista Brasileira de Geomorfologia, v. 6, n. 2, p. 29-41, 2005. 
BORGES, R. O; SILVA, R. A. A.; CAMPAGNOLI, F.; CASTRO, S. Mapeamentos da evolução da produção de sedimentos no setor sul da alta bacia do rio Araguaia. In: SIMPÓSIO NACIONAL DE CONTROLE DE EROSÃO, 8, São Paulo, 2009. Anais. São Paulo: Acqua, 2009.

CASTRO, S. S. Erosão hídrica na alta bacia do rio Araguaia: distribuição, condicionantes, origem e dinâmica atual. Revista do Departamento de Geografia, São Paulo, n. 17, p. 38-60, 2005.

CHRISTOFOLETTI, A. Análise morfométrica das bacias hidrográficas. Notícia Geomorfológica, Campinas, v. 9, n. 18, p. 35-64, 1969.

LACERDA FILHO, J. V. (Org.). Geologia e recursos minerais do estado de Goiás e do Distrito Federal. 2. ed. Goiânia: CPRM/METAGO/UnB, 2000. Esc. 1:500.000. Programa Levantamentos Geológicos do Brasil.

LATRUBESSE, E. M.; AMSLER, M. L.; MORAIS, R. P.; AQUINO, S. The geomorphology response of a large pristine alluvial river to tremendous deforestation in the South American tropics: the case of the Araguaia River. Geomorphology, v. 113, n. 3-4, p. 239-252, 2009.

MACKIN, J. H. Concept of the graded river. The Geological Society of America Bulletin, v. 59, p. 463-512, 1948.

MARINHO, G. V.; CASTRO, S. S.; CAMPOS, A. B. Hidrology and gully process in the upper Araguaia River basin, Central Brazil. Zeitschriftfür Geomorphologie, v. 145, n. suplementar, p. 119-145, 2006. (Edição Especial - Tropical Geomorphlogy: with special reference to South America).

MELIANI, P. F. Mapeamento da rede hidrográfica e análise dos parâmetros da densidade de drenagem aplicados ao estudo ambiental: o caso da bacia do rio Jeribucassu, Itacaré, Bahia. Geografia, Rio Claro, v. 31, n. 1, p. 119-136, jan./abr. 2006.

OLIVEIRA, V. C. V.; CASTRO, S. S. Susceptibility and risks to water erosion in the upper of Araguaia River basin (GO/MT), Brazil. Sociedade \& Natureza, Uberlândia, v. 1, n. 1, p. 697-708, 2005. (Edição especial - International Symposium on Land Degradation and Desertification).

ZANCOPÉ, M. H. C.; BAYER, M. Proposta metodológica para avaliar o potencial de transferência de sedimentos de bacias hidrográficas a partir de índices morfométricos. In: SIMPÓSIO NACIONAL DE GEOMORFOLOGIA, 9, Rio de Janeiro, 2012, Anais. Rio de Janeiro: UFRJ/UGB, 2012. p. 1-3.

ZANCOPÉ, M. H. C.; PEREZ FILHO, A. Considerações a respeito da distribuição das planícies fluviais do rio Mogi Guaçu. Revista Brasileira de Geomorfologia, v. 7, n. 1, p. 65-71, 2006.

ZANCOPÉ, M. H. C.; PEREZ FILHO, A.; CARPI JÚNIOR, S. Anomalias no perfil longitudinal e migração dos meandros do rio Mogi Guaçu. Revista Brasileira de Geomorfologia, v. 10, n. 1, p. 31-42, 2009. 
Márcio Henrique de Campos Zancopé - Possui Graduação em Geografia pela Universidade de São Paulo, Licenciatura em Geografia pela mesma Universidade. Possui Mestrado em Geografia pela Universidade Estadual Paulista e Doutorado em Geografia pela Universidade Estadual de Campinas. Atualmente é Professor na Universidade Federal de Goiás.

Paulo Eduardo Gonçalves - É estudante de Ciências Ambientais na Universidade Federal de Goiás. Foi bolsista PIBIC-CNPq/UFG e CAPES de graduação pelo Programa Ciências sem Fronteiras na Universidade de Pádua, Itália. Atualmente é estagiário no Laboratório de GIS do Departamento de Ciência Histórica, Geográfica e da Antiguidade, onde colabora com o Projeto Geoyasunì.

Maximiliano Bayer - Possui Graduação em Geologia pela Universidad Nacional de San Luis. Mestrado em Geografia pela Universidade Federal de Goiás. Doutorado em Ciências Ambientais pela mesma Universidade. Atualmente é Professor na Universidade Federal de Goiás.

Recebido para publicação em 17 de janeiro de 2015 Aceito para publicação em 12 de março de 2015 